\title{
BONDING DEVELOPMENT BETWEEN PARENTS AND CHILDREN THROUGH PLAYING TOGETHER TO IMPROVE HAPPINESS
}

\author{
Saptawati Bardosono, ${ }^{1}$ Rini Hildayani, ${ }^{2}$ Dian Novita Chandra, ${ }^{1}$ Yulianti Wibowo, ${ }^{3}$ Ray W. Basrowi ${ }^{3}$ \\ 1 Department of Nutrition, Medical Faculty Universitas Indonesia, Cipto Mangunkusumo Hospital \\ 2 Psychology Faculty, Universitas Indonesia \\ 3 Nestle Nutrition Institute Indonesia
}

Abstract - Introduction: This study aims to use the Indonesian translation of modified couple satisfaction index (CSI) tool to evaluate parental happiness scores at before and after participating playing together activities that was designed for bonding development between parents and children. Methods: By using a serial pre-post intervention experimental design, to assess a minimal of 263 couples of mothers and fathers having under fiveyear-old child at before after the intervention, and two weeks after. The intervention was playing activities in an interactive playground spent by parents and child for 1.5-2 hours that were located in Medan, Jakarta, Surabaya and Makassar. The validated CSI semi-structured questionnaire (by using Cronbach's alpha of $60 \%$ or more) was used to collect data to explore factors contributing to parents' happiness. A multiple measure analysis was used to analyse the parents' happiness improvements.

Results: The CSI tool was validated with the Cronbach's alpha of 0.87 and 0.84 for father and mother, respectively. This study could recruit a total of 370 couples, however only 282 couples completed all data collection. There are 11 items asked for parents' happiness, 3 items regarding to factors contributing to parents' happiness, and 6 items to assess parents' satisfaction. There are improvements in all items by proportions, and the total score of parents' feelings about their relationships are significantly increased by time $(\mathrm{P}<0.001)$.

Conclusion: The quality of playing together between parents and child can increase family happiness at both short and longer-periods.

Keywords: bonding development, parents and child, family happiness

\section{INTRODUCTION}

There is an indication that being a parent is associated with higher well-being or so called happiness. One main source of parents' happiness is their children. However, there are factors contributing to parents' happiness, among others are purpose or meaning in life, human needs, positive emotions, and social roles that have positive effects. On the opposite, negative emotions, financial strain, sleep disturbance and strained partner relationships contribute as negative effects to parents' wellbeing. ${ }^{1}$

Happiness itself is a culturally constructed concept that is defined internalized and socialized accordingly. ${ }^{2}$ Therefore, there is a need to use an assessment tool of happiness that is culturally specific. There are several tools available, and among others is the Subjective Happiness Scale (SHS) by Lyubomirsky and Lepper (1999) which is the most widely used short self-report to measure happiness across age. However this study decide to use the couples satisfaction index (CSI), ${ }^{3}$ the previous scale seems too general, while the CSI is more promising to measure one's satisfaction in a relationships, such as mother and/or father relationship to partner and/or under-five year old child.

In our knowledge, there is no study exploring the relationships between family happiness and child nutritional status yet. However, happy families are far more likely to be characterized by good family relationships that include mutual understanding and respect between parents and children. ${ }^{4}$ This condition could also be applied to family and child eating behavior. This study aims to use the Indonesian translation of modified CSI to evaluate parental happiness scores at before and after participating playing together activities that designed for bonding development between parents and children.

\section{METHODS}

\section{Study design}

This study implemented a serial pre-post intervention experimental design to evaluate parents' happiness at before and after the intervention, and two-weeks after the intervention 
that indicated the long-term effect. A preliminary study was conducted prior to the main study to validate the Indonesian translation of the modified CSI, and exploring factors contributing to parents' happiness and their satisfaction toward the intervention.

Type of activity applied for parents and child in this study was playing together in a playground. The activities was designed to encourage both parents and child to play/spend time together which enable to stimulate bonding and happiness between them. Playing activities provided in the playground namely fishing, feeding animals (cat, rabbit, deer and bird), taking picture with animal, snow playground and playing in the giant slide. There is no mandatory on the selection of activities should be followed by the parents and child in the playground, however the average time of playing among families was about 1.5-2 hr. Some families were able to participate in all activities provided but some were not. The CSI questionnaire was filled in by the parents at before and after playing in the playground.

\section{Place and Time}

The preliminary study was done in Jakarta to prepare the instrument for the main study $\left(1^{\text {st }}\right.$ of March 2016) while waiting for the formal release to ethics' letter. While the main study was conducted afterward in several big cities of Indonesia (MarchMay 2016), i.e. Jakarta ( $5^{\text {th }}$ of March and $28^{\text {th }}$ of May), Medan (14 ${ }^{\text {th }}$ of May), Surabaya $\left(19^{\text {th }}\right.$ of March), and Makassar (16 ${ }^{\text {th }}$ of April).

\section{Population and Subjects}

For the preliminary study, thirty mothers and fathers having children aged 1-5 years who lived in Jakarta and willing to join this study were asked to participate. While for the main study, mothers and fathers having children aged 1-5 years who were willing to participate in this study and sign the informed consent were included, and those could not finish the study protocol were not be included in the analysis.

\section{Sample Size Calculation}

For the preliminary study, a minimal of thirty eligible parents (mother and fathers) were sufficient to validate the Indonesian modified CSI in determining parents' happiness and exploring factors contributing to it. For the main study, minimal sample size was calculated to compare two or more paired means of SHS score. By using 95\% confidence interval and $90 \%$ of power to detect $10 \%$ of score improvement and assuming of standard deviation of $50 \%$, then a minimal sample size of each 263 mothers and fathers were needed. Consecutive sampling was used to get the eligible subjects in each location. By allowing $40 \%$ of drop out or no response rate, then this study should get a minimal 300 mothers and 300 fathers to be included in the analysis.

\section{Data Collection}

The English version of modified the Couples Satisfaction Index (CSI) was first translated into Bahasa Indonesia and then was back translated into English at before being used for the validation/preliminary study. After screening of the subjects for the preliminary study then a minimal of 30 mothers and 30 fathers were asked to fill in the Indonesian version of modified CSI, and followed by filling in a semi-structured questionnaire to explore factors contributing to parents' happiness.

After validating the Indonesian version modified CSI, then the modified CSI was used to for data collection in the main study at before and after participating to the playing together activities, and was repeated after two weeks later. Besides, a satisfactory tool was also employed to evaluate parents' satisfaction toward the intervention.

The intervention was a playground set-up in a special area in the mall, which included several activation sections. In each section visited, parents should accompany and play together with their child. The following are variables understudy: Parents' happiness, is defined as a mental or emotional state of well-being defined by positive or pleasant emotions ranging from contentment to intense joy, that can be evaluated by using modified the Couples Satisfaction Index (CSI) tool and graded from score 0 to 6 and/or 0 to 5. Factors contributing to parents' happiness are including several conditions that could have positive and negative effect to parents' happiness, categorized to 1 as having the positive or negative factor and 0 as else. ${ }^{1}$ Parents' satisfaction, is defined as a happy or pleased feeling because of something done or happened. 


\section{Data Management and Analysis}

Subjects' characteristics were analyzed descriptively by using central tendency and/or frequency distribution (n, \%). Validation of CSI tool used Cronbach's Alpha of $60 \%$ or more to determine that the tool is valid. And, a dependent- $t$ test and/or multiple measure analyses were used to evaluate the score improvements at before and after the intervention.

\section{Ethical Consideration}

Ethical clearance approval was received from the Ethical committee Faculty of Medicine Universitas Indonesia, i.e. No. 275/UN2F1/ETIK/2016 by April 4, 2016.

\section{RESULTS}

The preliminary study has done a translation and back-translation of the instrument used in this study by a sworn formal translators. Furthermore, by using 30 subjects of fathers and mothers of underfive children, we did a reliability test and had a good reliability for both father and mother with a Cronbach's Alpha of 0.87 and 0.84, respectively, showing that the tool is valid.

This study could get 370 subjects of each mother and father who had children age 1-5 years old to participate at baseline, as shown in Figure 1. respectively. The response rate is still higher than the expected of $60 \%$ and still fulfilled the minimal sample size of this study (i.e. 263 pairs of father and mother).

Table 1 shows the socio-demographic characteristics of the subjects in total and by the study locations. In general, the child sex was comparable, with a high education parents, permanent job for father and approximately onethird of the mothers are working. Thus, the family income is found to be sufficiently high and more than half of the families owned their house.

Furthermore, Table 2 shows that most of the subjects has a nuclear family type (75\%), had approximately five years of marriage and mostly brought their owned first born child to the playground intervention place (72\%). They mostly have one child of their own (56\%).

Almost all of the parents perceived no problem in taking care of their child. While the main child caregiver is mother $(80 \%)$, as shown in Table 3.

\section{Parents' happiness}

By participating in the playground intervention program, Figure $2 \mathrm{a}$ and $2 \mathrm{~b}$ show that there are more than $20 \%$ increased proportions on several aspects of happy characteristics during and after the intervention both for fathers and mothers. There are

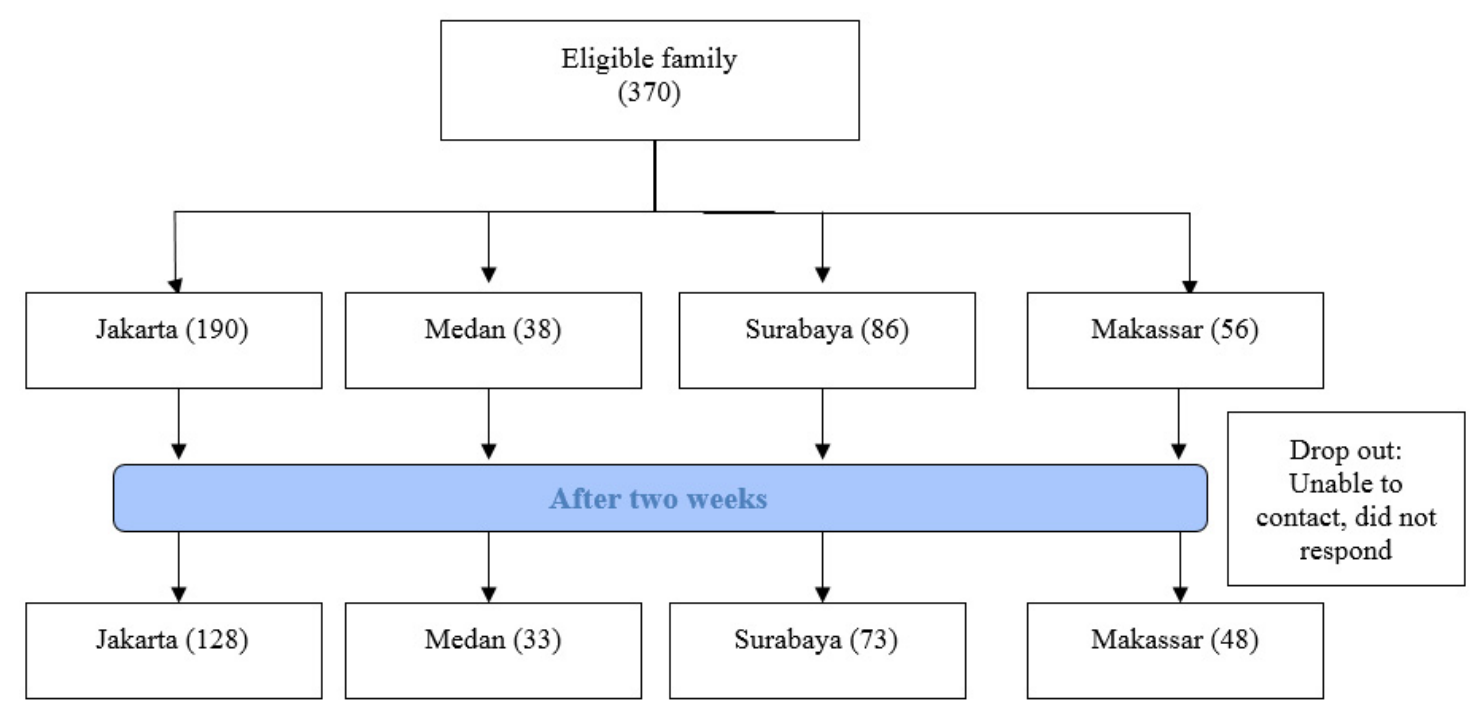

Figure 1. The study workflow

However, the response rate after the two weeks intervention, in average was $76.2 \%$ (282 subjects of father and mother), i.e. $67.4 \%, 86,8 \%, 84.9 \%$ and $85.7 \%$ in Jakarta, Medan, Surabaya and Makassar,
11 items (item A to item K) to measure parents' happiness, i.e. changing in perfect degree of happiness (in \%) at before and after attending the playground (item A), changing in the approximate 
Table 2. Family status characteristics distribution of the subjects $(n=370)$

\begin{tabular}{|c|c|c|c|c|c|c|}
\hline Variables & $\begin{array}{c}\text { Jakarta } 1 \\
\mathrm{n}=100\end{array}$ & $\begin{array}{c}\text { Surabaya } \\
n=86\end{array}$ & $\begin{array}{c}\text { Makassar } \\
\mathrm{n}=56\end{array}$ & $\begin{array}{c}\text { Medan } \\
\mathrm{n}=38\end{array}$ & $\begin{array}{c}\text { Jakarta } 2 \\
\mathrm{n}=90\end{array}$ & $\begin{array}{c}\text { Total } \\
\mathrm{n}=370\end{array}$ \\
\hline \multicolumn{7}{|l|}{ Family status, n (\%) } \\
\hline Nuclear & $77(77)$ & $57(66.3)$ & $30(53.6)$ & $34(89.5)$ & $79(87.8)$ & $277(74.9)$ \\
\hline Extended & $23(23)$ & $29(33.8)$ & $26(46.4)$ & $4(10.5)$ & $11(12.2)$ & $93(25.1)$ \\
\hline Length of marriage & $5.5(2-20)$ & $5(1-20)$ & $5(2-14)$ & $6(2-14)$ & $5.0(2.5-15.0)$ & $5(1-20)$ \\
\hline $\begin{array}{l}\text { Length of having the child } \\
\text { Child status, } \mathrm{n}(\%)\end{array}$ & $3(0-8)$ & $3(0-13)$ & $2(1-12)$ & $2.5(1-9)$ & $3.3(1.0-5.5)$ & $3(0-13)$ \\
\hline Own child & $100(100)$ & $86(100)$ & $56(100)$ & $37(97.4)$ & $90(100.0)$ & $369(99.7)$ \\
\hline Adopted child & - & - & - & $1(2.6)$ & - & $1(0.3)$ \\
\hline \multicolumn{7}{|l|}{ Child rank, n (\%) } \\
\hline First & $58(58)$ & $62(72.1)$ & $44(78.6)$ & $20(52.6)$ & $72(80.0)$ & $272(73.5)$ \\
\hline Second & $32(32)$ & $18(20.9)$ & $10(17.9)$ & $14(36.8)$ & $16(17.8)$ & $77(20.8)$ \\
\hline Third and more & $10(7)$ & $6(7.0)$ & $2(3.6)$ & $4(10.5)$ & 2. (2.2) & $21(5.7)$ \\
\hline \multicolumn{7}{|l|}{ Number of children, $\mathrm{n}(\%)$} \\
\hline 1 & $58(58)$ & $50(58.1)$ & $29(51.8)$ & $15(39.5)$ & $58(64.4)$ & $210(56.8)$ \\
\hline 2 & $32(32)$ & $28(32.6)$ & $24(42.9)$ & $18(47.4)$ & $26(28.9)$ & $128(34.6)$ \\
\hline 3 and more & $10(10)$ & $8(9.3)$ & $3(5.4)$ & $5(13.1)$ & $6(6.6)$ & $32(8.6)$ \\
\hline
\end{tabular}

extent of always agree between parents and the child for the amount of time spent together (in \%) at before and after attending the playground (item B), changing in the approximate extent of always agree between parents and the child for the affection demonstrated each other (in \%) at before and after after attending the playground (item F), changing in a warm and comfortable relationship that is completely true between parents and the child (in $\%$ ) at before and after attending the playground (item $\mathrm{G}$ ), changing in feeling like part of a team that is completely true between parents and the child (in

\begin{tabular}{|c|c|c|c|c|c|c|}
\hline Variables & $\begin{array}{c}\text { Jakarta } 1 \\
\mathrm{n}=100\end{array}$ & $\begin{array}{c}\text { Surabaya } \\
n=86\end{array}$ & $\begin{array}{c}\text { Makassar } \\
\mathrm{n}=56\end{array}$ & $\begin{array}{c}\text { Medan } \\
\mathrm{n}=38\end{array}$ & $\begin{array}{c}\text { Jakarta } 2 \\
n=90\end{array}$ & $\begin{array}{c}\text { Total } \\
\mathrm{n}=370\end{array}$ \\
\hline \multicolumn{7}{|l|}{ Problems in child caring, $\mathrm{n}(\%)$} \\
\hline Father & $98(98)$ & $83(96.5)$ & $55(98.2)$ & $38(100.0)$ & $90(100.0)$ & $364(98.4)$ \\
\hline Mother & $96(96)$ & $82(95.3)$ & $56(100)$ & $38(100.0)$ & $89(98.9)$ & $361(97.6)$ \\
\hline \multicolumn{7}{|l|}{ Main childcare provider, $\mathrm{n}(\%)$} \\
\hline Father & $1(1)$ & $1(1.2)$ & - & $3(7.9)$ & $1(1.1)$ & $6(1.6)$ \\
\hline Mother & $72(72)$ & $64(74.4)$ & $51(91.1)$ & $32(84.2)$ & $76(84.4)$ & $295(79.7)$ \\
\hline Grandparents & $18(18)$ & $14(16.3)$ & $4(7.1)$ & $2(5.3)$ & $11(12.2)$ & 49 (13.2) \\
\hline Others & $9(9)$ & $7(8.1)$ & $1(1.8)$ & $1(2.6)$ & $2(2.2)$ & $20(5.4)$ \\
\hline
\end{tabular}

attending the playground (item $\mathrm{C}$ ), changing in the strong connection that is completely true between parents and the child for the affection demonstrated each other (in \%) at before and after attending the playground (item D), changing in the strong relationship that is completely true between parents and the child for the affection demonstrated each other (in \%) at before and after attending the playground (item E), changing in the relationship that is completely true between parents and the child that make them happy (in \%) at before and
$\%)$ at before and after attending the playground (item $\mathrm{H}$ ), changing in imagining another person to make as happy that is completely true as their child (in \%) at before and after attending the playground (item I), changing in rewarding completely (in \%) in the relationship with the child at before and after attending the playground (item J), and changing in satisfaction completely (in \%) with the child at before and after attending the playground (item K).

\section{Factors contributing to parents' happiness}


Based on the subjective semi-quantitative score on the quality of relationships between fathers and mothers to the child, there are varied findings on the changing in the proportion toward better 


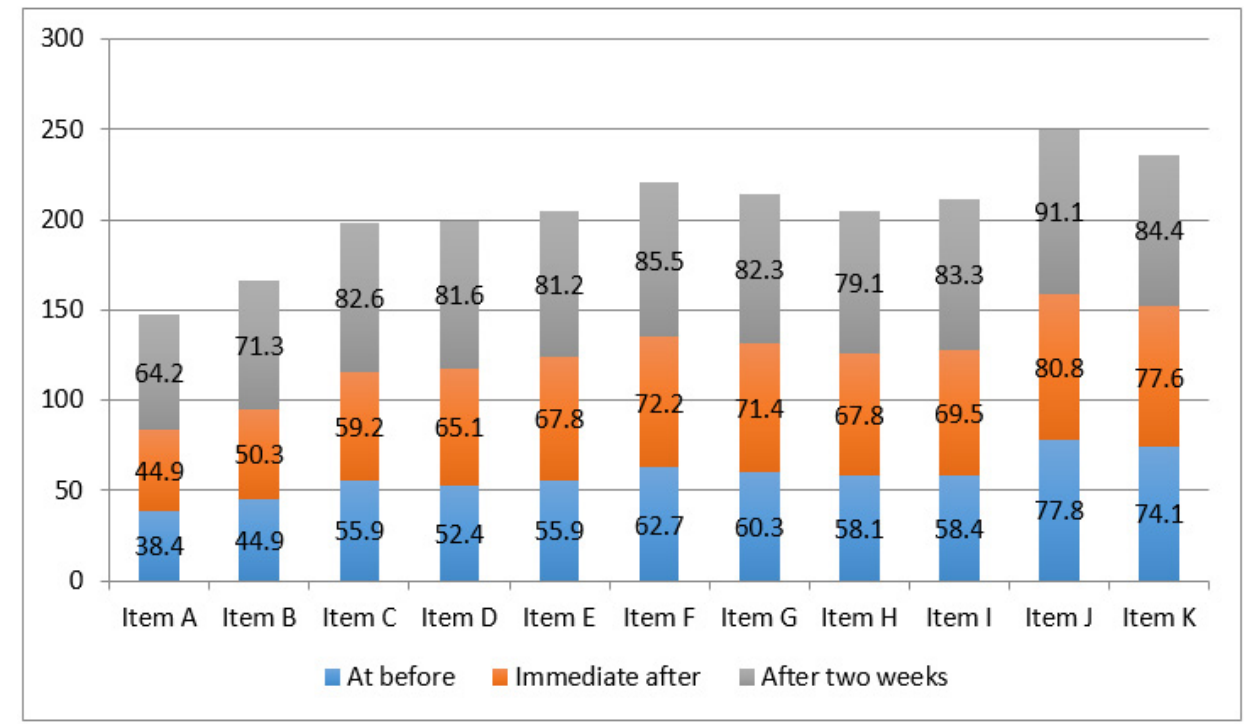

Figure 2a. Fathers' happiness at before and after the intervention

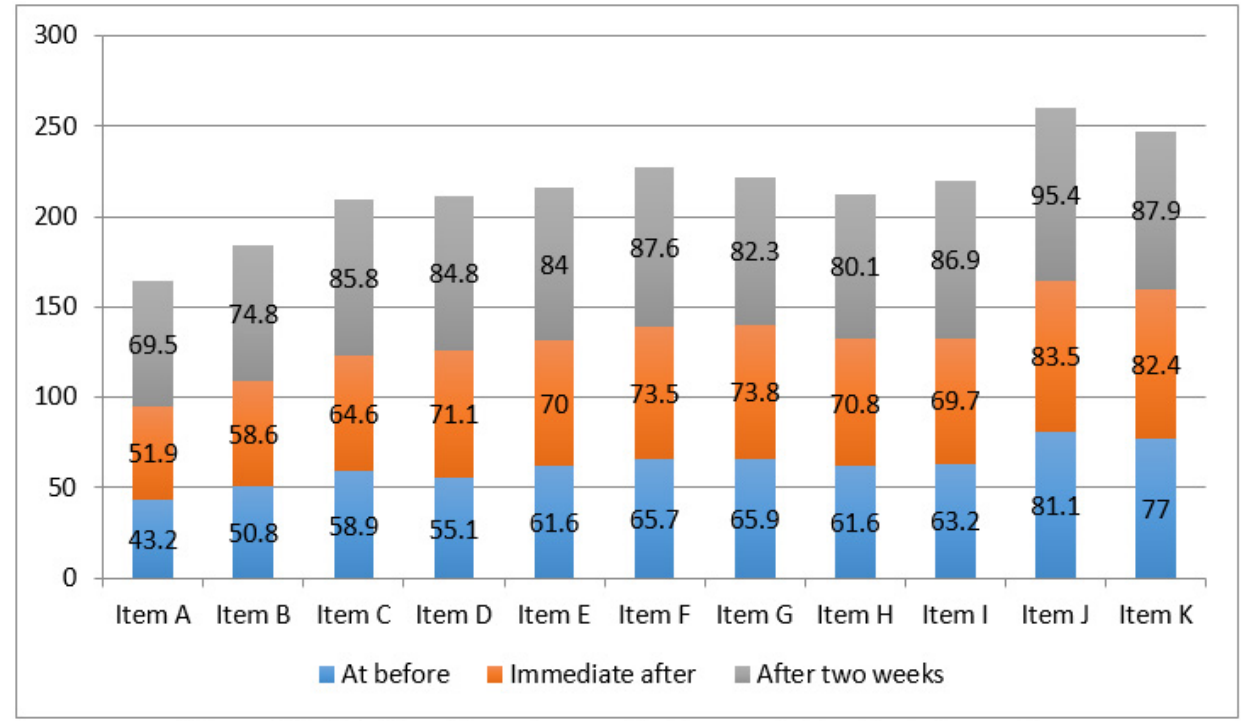

Figure 2b. Mothers' happiness at before and after the intervention

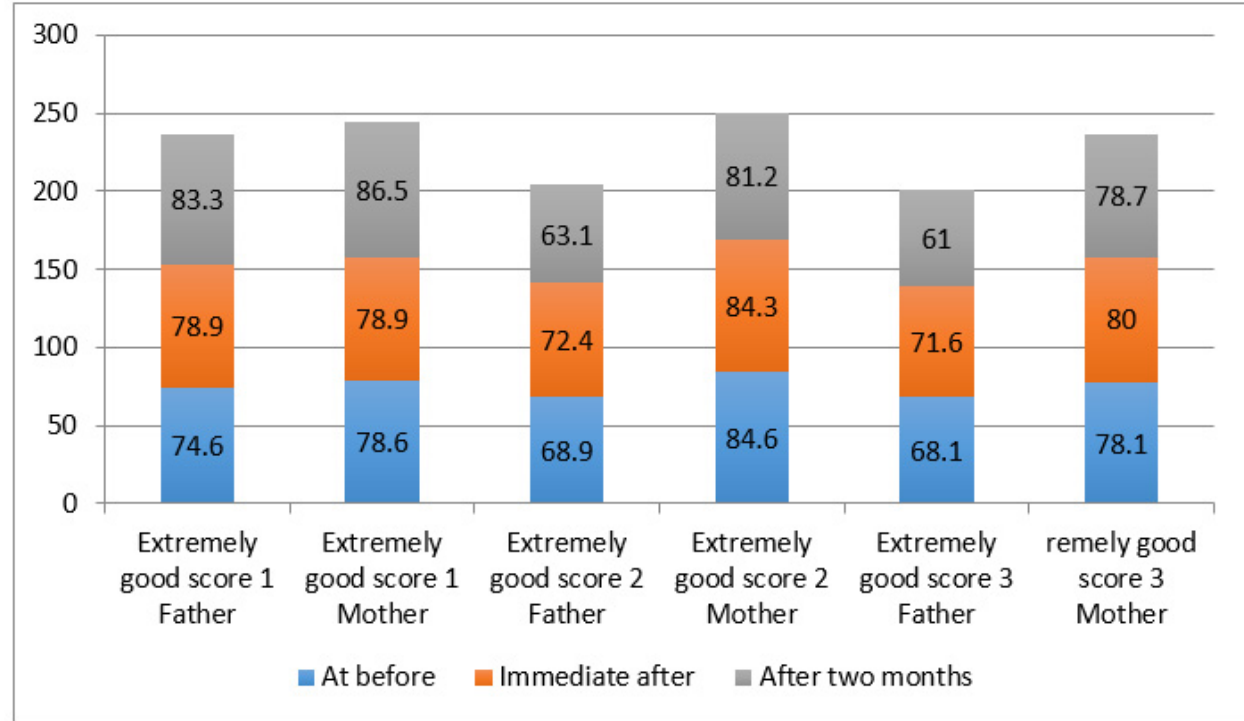

Figure 3. Factors contributing to parents' happiness at before and after the intervention

relationships, especially for fathers (Figure 3). the study, i.e. changing in extremely good score (in There are three indicators being compared during \%) in relationship with the child at before and after 
attending the playground, changing in more often (in \%) in enjoying the companionship with the child at before and after attending the playground, and changing in more often (in \%) in having fun together with the child at before and after attending the playground. The finding shows that more often in enjoying the companionships (score 1 and score 2) with the child are both decreased, for father and mother. More often having fun together (score 3) is slightly increased for mother but decreased for father.

\section{Parents' satisfactions}

Further more, based on the first impression and immediate feeling about how the father and mother feel about the relationship with the child, Figure 4 in the feeling about the relationship with the child at before and after attending the playground.

However, Figure 5 shows that in term of overall scoring, the total score of the feeling about their relationship are significantly increased by time, both for father and mother $(\mathrm{P}<0.001)$.

\section{DISCUSSION}

We understand that the majority of children in the developing world, including Indonesia are not able to reach their full developmental potential as the results of poverty, undernutrition, micronutrient deficiencies, and learning environments as well as parental home stimulation activities that do not provide enough responsive stimulation and

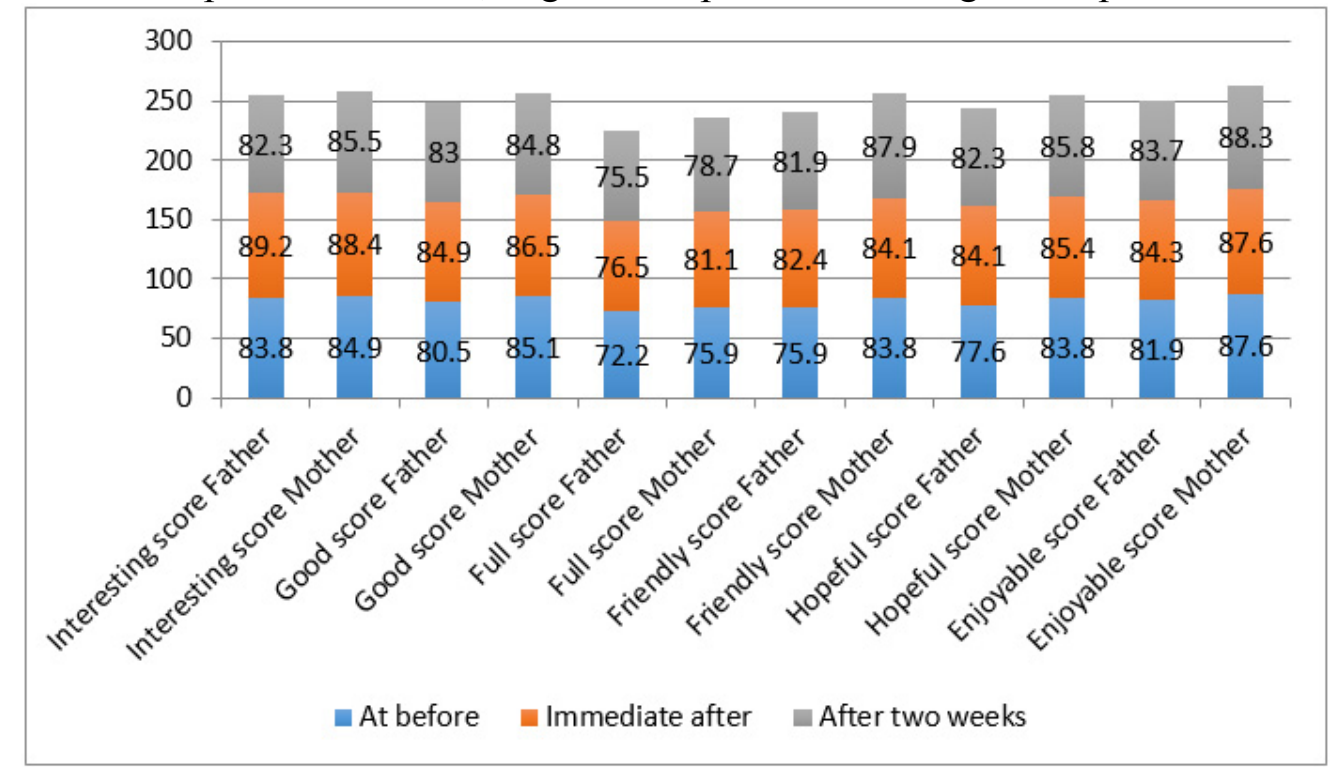

Figure 4. Parents' satisfactions at before and after the intervention

show slightly increased on their feelings (less than $10 \%$ ). The six satisfaction indicators used were as follows: changing in interesting score (in \%) in the feeling about the relationship with the child at before and after attending the playground, changing in good score (in \%) in the feeling about the relationship with the child at before and after attending the playground, changing in full score (in $\%)$ in the feeling about the relationship with the child at before and after attending the playground, changing in friendly score (in \%) in the feeling about the relationship with the child at before and after attending the playground, changing in hopeful score (in \%) in the feeling about the relationship with the child at before and after attending the playground and changing in enjoyable score (in \%) nurturance which affecting of their wellbeing or happiness. $^{5-7}$ Exploration on the happiness indicators of the Malaysians and Indonesians, revealed that there are 12 happiness indicators in which the first mentioned is family from the others, i.e. career, interpersonal and social relationships, self-growth/self-autonomy, wealth, recreation, needs, education, absence from negative feelings, national prosperity, health, religion, and basic needs. ${ }^{5}$

This study is the first study to explore the bonding (strong connection) development between parents and children through playing together in improving family happiness in Indonesia, represented by parents and children in several big cities such as Jakarta, Surabaya, Medan and Makassar. We found that based on the total score in 


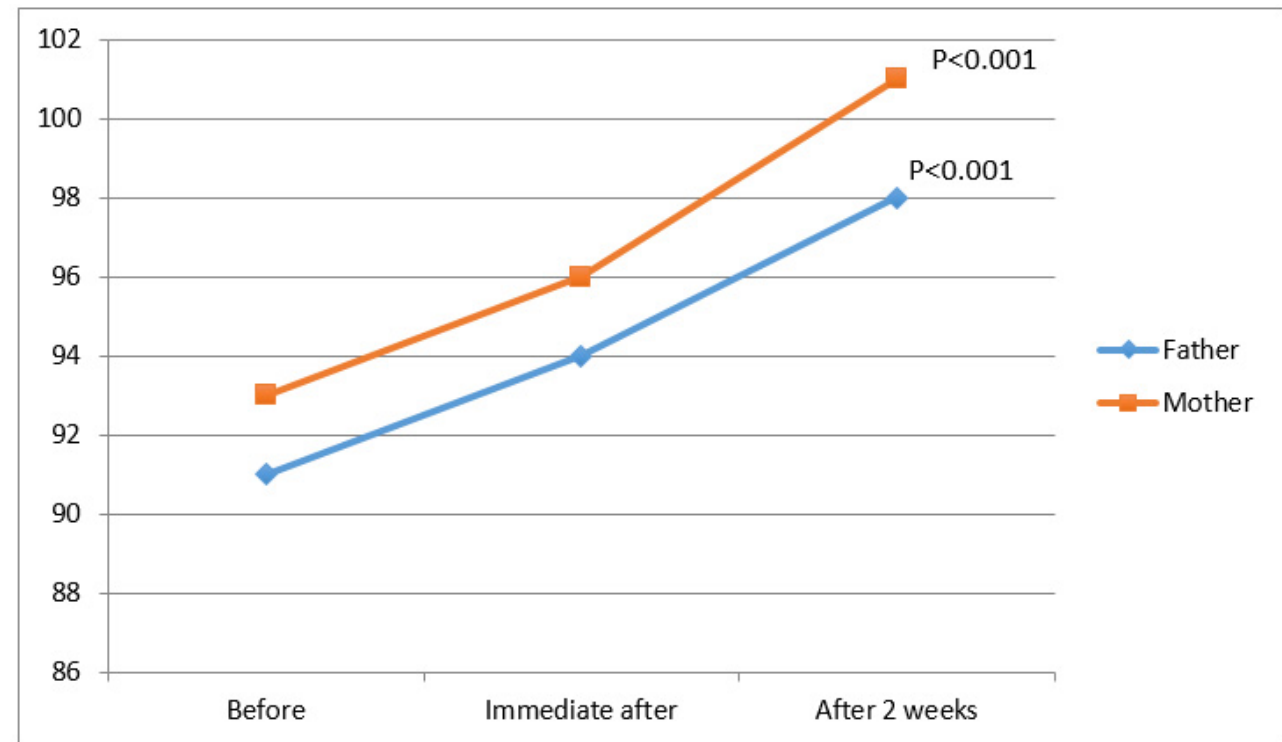

Figure 5. Changing in total score (in median value) in the feeling about the relationship with the child at before and after attending the playground

the feelings about the relationships of parents, both fathers and mothers with the child, there were score increments between before, immediate after, and after the two weeks attending the playground activities/stimulation. These increments in the total score, in details are contributed from the score increments (more than 10\%) of the proportions on degree of happiness, spending time together, showing affection, strong connection, strong, happy, warm-comfortable relationships, a solid team, make them feel more happy, rewarding, satisfaction relationships with the child, as reported by both father and mother. It is well defined that the first few years of life are particularly important in which vital development occurs in all domains through brain development. Child's development, besides of genetic inheritance, it is affected by both psychosocial and biological factors. Therefore, early undernutrition, iron-deficiency, environmental pollutions, stress, poor stimulation and social interaction can affect brain structure and function, and have lasting cognitive and emotional effects, such as happiness. ${ }^{8}$ A happy family is a good environment for child development and growth. Happy family can be created if the parents and the child are happy.

Happiness in the family is like a circle. It depends on the happiness of every member of the family, i.e. father, mother and the child. Thus, parents will be happy as long as the child happy. Vice versa, the child can be happy if the parents who care for and nurture them is happy. A feeling of happiness that is always embedded in the family can create a healthy emotion that is good for the child development. However, in most Asian countries, especially those with the Confucian cultures, they score very low in happiness survey. There are some speculate reasons, such as environmental disruption, excessive competitiveness, repressive education, excessive conformity, negative attitudes towards enjoyment, and the emphasis on outward appearance. ${ }^{9}$ Besides, family happiness is influenced by four broad factors, i.e. family type (nuclear or extended, married, single or separated, etc), family processes (inter-generational history of family relationships, attitudes to parenting and family roles, etc), individual characteristics (personality traits, such as positive and negative emotionality as well as psychological independence and interdependence), and family circumstances (life events, education, social class, hours worked, etc). ${ }^{10}$ However, demographic variables related to the family, i.e. number of siblings, age of parents, and marital status of parents) were only weakly, or not at all, associated with children's happiness. While social relationships are significantly correlates and predictors of happiness. ${ }^{11}$

Related to fathers' involvement, it revealed that children, since infants of highly involved fathers, as measured by amount of interaction, including higher level of play and caregiving activities, are more cognitively competent at 6 months and score higher on the Bayley Scales of 
Infant Development. By one year they continue to have higher cognitive functioning, are better problem solvers as toddlers, and have higher IQ's by age three. When compared with mothers, fathers' talk with toddlers is characterized by more "wh" questions, such as what, where, etc that requires children to assume more communicative responsibility in the interaction. This encourage toddler to talk more, use more diverse vocabulary, and produce longer utterances when interacting with their fathers. Father involvement is positively correlated with children's overall life satisfaction and their experience of less depression, less emotional distress, less expressions of negative emotionality, such as fear and guilt, less conduct problems, greater sense of social competence, higher levels of self-reported happiness, fewer anxiety symptoms, and lower neuroticism. ${ }^{12}$ However, in relation to emotional intelligence, parental bonding style of fathers has an effect only to the level of child motivation and empathy, while the parental bonding style of mothers affects child self-awareness, self-regulation, motivation, empathy and social skills. We are aware that high level of emotional quotients may contribute to child development. ${ }^{13}$ Thus, the children need both parental bonding style from fathers and mothers. And, playing together has been proven can improve family happiness as it can increase the affection, bonding (strong connection), warmth, compactness, and makes the relationship between parents and child more enjoyable. When playing, child becomes happy and relaxed, and so the brain will in a happy state as well. And, when the brain is in the positive state, then through a brain and gut cross talk, child digestion will be healthier. And, vice versa, a healthy digestive system can help the child to enjoy playing and absorb the benefits properly, so they could be happier.

However, we have to ensure that the child can play comfortably, and absorb the benefits of playing to the fullest, then parents should provide the child with nutrition that are good for their digestion, such as energy (carbohydrates, essential amino-acids, omega-3 fatty acids and water), vitamins (A and B's), and minerals (zinc). Besides, it is also important for parents to maintain the hygiene while playing with the child by ensuring the child has a good immune system. The largest immune system is in the gut. Thus, one of the most important steps to take is to maintain a healthy digestive system of the child, such as providing probiotics intake from the child meals and drinks. ${ }^{14,15}$

However, this study also found that the opportunity to be together in the playground did not significantly prove yet to increase the level of scores on their extremely good relationship, more often enjoying being together and having fun together. Actually, by doing activities like playing together, parents and the child can interact and communicate each other. Interaction and communication are the most important basic elements in increasing happiness, besides can show their affection to one another. ${ }^{16}$ It is also related to the finding in this study that did not significantly changes on the scores for being more interesting, having good, full, friendship, hopeful, and enjoyable feeling about the parents' relationships with the child after attending the playground. Besides the limited available time provided, unfortunately most parents were not familiar with existing parenting programs. ${ }^{17}$ Actually, while playing together, the connection or relationship between parents and the child can grow stronger and in returns can create a feeling of belonging (family as one unity or a team). Besides, playing activities can also be utilized to optimize child's growth and character development. This study has a limitation for not trying to elaborate the bonding development but more to identify parents' emotional perception toward happiness in a short (i.e. after playing together) and in a longer time (i.e. after two weeks).

In conclusions, it is not the playground itself as the only type of stimulation, or the length of playing time spent together, but the quality of playing together between parents and the child that can increase family happiness at immediate after and even weeks after, because parents feel happy when seeing their child happy by doing any playing activity.

\section{Conflicts of Interest}

The authors of this paper declare there is no conflict of interest regarding this research.

\section{Acknowledgment}

We would like to acknowledge the critical and editorial contribution to this and an earlier version of the paper by Pittara Pansawira. Her patience and persistence in following 
up the production of the paper has been exceptional.

\section{REFERENCES}

1. Nelson SK, Kushlev K, Lyubomirsky S. The pains and pleasures of parenting: When, why, and how is parenthood associated with more or less well-being? Psychol Bull. 2014;140(3):846-95.

2. Moghnie L, Kazarian SS. Subjective Happiness of Lebanese College Youth in Lebanon: Factorial Structure and Invariance of the Arabic Subjective Happiness Scale. Soc Indic Res. 2012 Nov;109(2):203-10.

3. Funk JL, Rogge RD. Testing the ruler with item response theory: Increasing precision of measurement for relationship satisfaction with the Couples Satisfaction Index. J Fam Psychol. 2007;21(4):572-83.

4. UNICEF. Happiness and families with children in Serbia: How to design public policies for the well-being of families with children. Available from: http://www.unicef.org/serbia/StudijaoSreciIntegralno.pdf.

5. Heilmann S. Life-chances of children in Indonesia: the links between parental resources and children's outcomes in the areas of nutrition, cognition and health. A thesis of the London School of Economics for the degree of Doctor of Philosophy. 2013 London;

6. UNICEF. Programming experiences in early child development. 2006 Nov; Available from: www.unicef.org/earlychildhood

7. Fernald LCH, Kariger P, Hidrobo M, Gertler PJ. Socioeconomic gradients in child development in very young children: Evidence from India, Indonesia, Peru, and Senegal. Proc Natl Acad Sci. 2012 Oct 16;109(Supplement_2):17273-80.

8. Grantham-McGregor S, Cheung YB, Cueto S, Glewwe P, Richter L, Strupp B. Developmental potential in the first 5 years for children in developing countries. The Lancet. 2007 Jan;369(9555):60-70.

9. Ng Y-K. The East-Asian happiness gab: speculating on cause and implications. Pacific Economic Review. 2002;7(1):51-63.

10. McKeown K, Pratschke J, Haase T. Family well-being: what makes a difference? Dublin: Kieran McKeown Limited; 2003.

11. Holder MD, Coleman B. The Contribution of Social Relationships to Children's Happiness. J Happiness Stud. 2009 Jun 1;10(3):329-49.

12. Allen SM, Daly KJ, Father Involvement Research Alliance, University of Guelph, Centre for Families W and W-B. The effects of father involvement: an updated research summary of the evidence [Internet]. Guelph, ON: Centre for Families, Work \& Well-Being, University of Guelph; 2007 [cited 2017 Jul 15]. Available from: http://www.deslibris.ca/ID/218523

13. Butalid R, Estacio K, Gadian C, Sisican J. Analysis between the parental bonding styles and emotional intelligence of student nurses. Proceedings of the $3 \mathrm{rd}$ annual International Conference Syiah Kuala University; 2013.
14. Graf D, Di Cagno R, Fåk F, Flint HJ, Nyman M, Saarela $\mathrm{M}$, et al. Contribution of diet to the composition of the human gut microbiota. Microb Ecol Health Dis [Internet]. 2015 Feb 4 [cited 2017 Jul 15];26(0). Available from: http://www.microbecolhealthdis.net/index.php/mehd/art icle/view/26164

15. Kau AL, Ahern PP, Griffin NW, Goodman AL, Gordon JI. Human nutrition, the gut microbiome and the immune system. Nature. 2011 Jun 15;474(7351):32736.

16. Jaafar JL, Idris MA, Ismuni J, Fei Y, Jaafar S, Ahmad $Z$, et al. The Sources of Happiness to the Malaysians and Indonesians: Data from a Smaller Nation. Procedia - Soc Behav Sci. 2012 Dec;65:549-56.

17. Sumargi A, Sofronoff K, Morawska A. Understanding Parenting Practices and Parents' Views of Parenting Programs: A Survey Among Indonesian Parents Residing in Indonesia and Australia. J Child Fam Stud. 2015 Jan 1;24(1):141-60. 